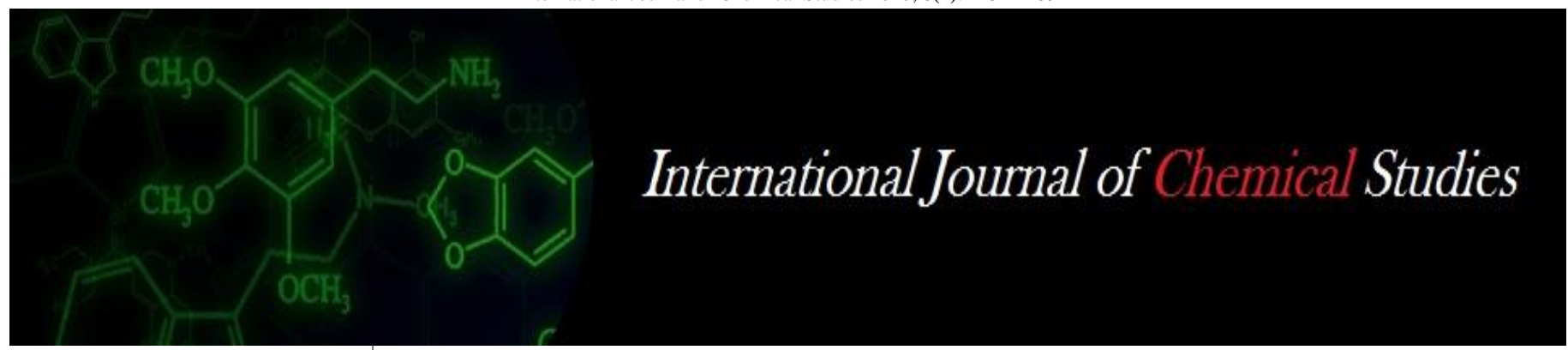

P-ISSN: 2349-8528

E-ISSN: 2321-4902

www.chemijournal.com

IJCS 2020; 8(4): 2451-2459

(C) 2020 IJCS

Received: 22-05-2020

Accepted: 24-06-2020

\section{S Arathi}

Research Scholar, Biofuel

Research Laboratory,

Department of Microbiology,

School of Life Sciences, Central

University of Tamil Nadu,

Thiruvarur, Tamil Nadu, India

\section{J TharunKumar}

Research Scholar, Biofuel

Research Laboratory,

Department of Microbiology,

School of Life Sciences, Central

University of Tamil Nadu,

Thiruvarur, Tamil Nadu, India

\section{K Jothibasu}

Assistant Professor, Department of Microbiology, PRIST,

Institution Deemed to

University, Thanjavur, India,

India

\section{S Karthikeyan}

Professor, Biomass Refining Lab, Department of Renewable

Energy Engineering, Tamil Nadu Agricultural University,

Coimbatore, Tamil Nadu

\section{R Suchitra}

Assistant Professor, Biofuel

Research Laboratory,

Department of Microbiology,

School of Life Sciences, Centra

University of Tamil Nadu,

Thiruvarur, Tamil Nadu, India

Corresponding Author:

\section{R Suchitra}

Assistant Professor, Biofuel

Research Laboratory,

Department of Microbiology,

School of Life Sciences, Central

University of Tamil Nadu,

Thiruvarur, Tamil Nadu, India

\section{Qualitative and quantitative estimation of algal lipids for biofuel production}

\section{S Arathi, J Tharun Kumar, K Jothibasu, S Karthikeyan and R Suchitra}

DOI: https://doi.org/10.22271/chemi.2020.v8.i4ab.10003

\begin{abstract}
The current rising demand for energy, global warming, and depletion of fossil fuels have led to increased consideration of alternate renewable biofuel sources. Microalgae serve as an excellent feedstock for biofuel production. Many qualitative and quantitative methods are available for lipid estimation from microalgae. In this review, we describe the various lipid estimation methods. Among the various methods discussed viz., conventional, and non-conventional methods, Nile red method offers a high throughput technique for rapid screening of high neutral lipid producing microalgae.
\end{abstract}

Keywords: Biodiesel, spectroscopy, neutral lipids, staining, fatty acid

\section{Introduction}

The best alternative to meet the existing and future demand for fuel is to replace it with renewable biofuels. Biofuels not only serves as an alternative to fossil fuels but also prevents the emission of harmful gaseous pollutants (Chen et al., 2018) ${ }^{[15]}$. Guo et al. (2015) ${ }^{[23]}$ have reported that biofuels exist in various forms like solids (charcoal, sawdust, etc.), liquid (bioethanol, biodiesel, etc), and gaseous (biogas, bio-syngas, etc). The major concerning issue with the commercialization of biofuel is its high cost of downstream processing (Yan et al., 2014) ${ }^{[73]}$.

Based on the feedstocks used, biofuels are classified into a) primary and b) secondary biofuels. Primary biofuel is referred to as natural biofuels. This is obtained from materials like firewood, wood chips, animal waste, etc. secondary biofuels are further classified into a) Firstgeneration - The feedstocks used are food crops like wheat, barley, corn, coconut, etc. which are grown on arable lands. The use of arable lands for biofuel production resulted in less available land for human and animal food production. b) Second-generation, The feedstocks used are non-food crops such as jatropha, cassava etc and non-edible parts of food crops like corn, sugarcane, etc. unlike crop plants, it grows on marginal lands. The feedstocks include lignocellulosic woody biomass which will not interfere with the food source and chain of the human (Alam et al., 2012) ${ }^{[2]}$. Waste frying oil can also be used as a feedstock but it results in high viscosity due to its high free fatty acid content (Menard et al., 2018) ${ }^{[47]}$ and c) the third generation biofuels- Algae with high lipid content is used as a source for fuel extraction. Algae are photoautotrophic organisms that will accumulate a certain amount of lipids and carbohydrates during their metabolic processes which can be used in extracting the fuel. Microalgae can produce different renewable biofuels such as methane, biodiesel, biohydrogen, etc., (Rajkumar et al., 2014) ${ }^{[56]}$. Microalgae, similar to higher plants produce both neutral and polar lipids. Polar lipids like glycolipids and phospholipids are produced under favorable conditions. These enrich the cellular and chloroplast membrane compositions. But, under unfavorable conditions like nutrient stress mainly nitrogen starvation, these algae alter their biochemical pathways to produce non- polar (or) neutral lipids such as triacylglycerols which accumulate in the cytoplasm as lipid droplets and are involved in energy storage (Held and Raymon, 2011; Aratboni et al., 2019) [32, 3]. Microalgae have potential as feedstocks for biodiesel (Singh and Dhar, 2011; Suchitra et al., 2014; Suchitra et al., 2015) ${ }^{[63,65-66]}$ besides their value as a source of bioactive molecules, nutraceuticals, and pigments (Gupta et al., $2013)^{[29]}$. Figure 1 has shown a flowchart for various methods of algal lipid estimation. 


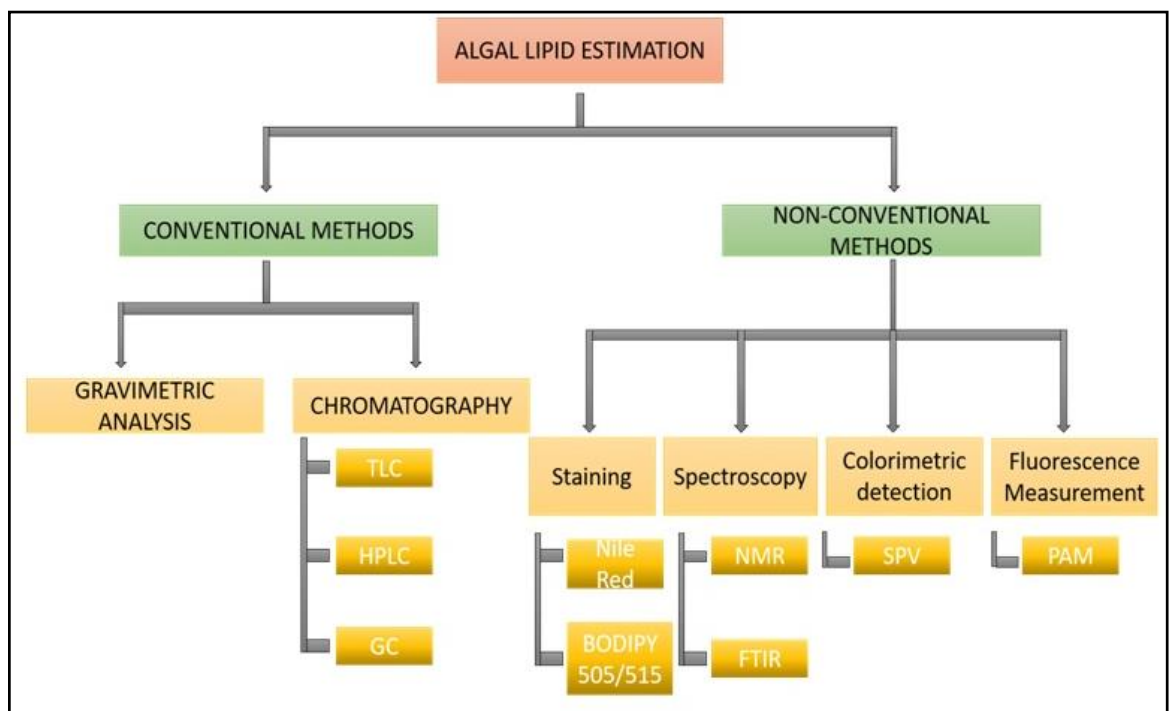

Fig 1: Flowchart for algal lipid estimation by various methods

\section{Algal lipids}

Algae comprise most of the major classes of lipids like glycolipids, phospholipids, triacylglycerols, hydrocarbons, sterols, etc (Beisson and Harwood, 2019) [6]. Microalgae comprise unsaturated fatty acids like palmitoleic, oleic, linoleic, linolenic acid, and a small amount of saturated fatty acids like palmitic and stearic acid. One of the disadvantages of using highly unsaturated sources includes complications related to contamination due to sediment formation as a result of oxidation. So, the composition is very much important concerning feedstock for biofuel production (Parveen et al., 2015) ${ }^{[54]}$. Polyunsaturated fatty acids (PUFAs) are derived from polar lipids which consist of long-chain fatty acids. PUFAs include docosahexaenoic acid, docosapentaenoic acid, eicosapentaenoic acid, hexadecadienoic acid, hexadecatrienoic acid, linoleic acid, etc as shown in Table 1. These can be used in biofuel production and can also be used in the field of medicine to treat diseases like atherosclerosis, Parkinson, and Alzheimer (Aratboni et al., 2019) ${ }^{[3] .}$

Table 1: Fatty acid composition (\% of total lipids) of the various microalgae strains

\begin{tabular}{|c|c|c|c|c|c|c|c|c|c|c|c|c|}
\hline Organism & $16: 0$ & $16: 1$ & $16: 2$ & $16: 3$ & $18: 0$ & $18: 1$ & $18: 2$ & $18: 3$ & $18: 4$ & 20: & $20: 5$ & References \\
\hline Chlorella vulgaris & 11.3 & 15.6 & - & 9.7 & - & 2.9 & 24.9 & 29.5 & - & - & - & \multirow{3}{*}{$\begin{array}{c}\text { Beisson et al., } \\
2019\end{array}$} \\
\hline Nannochloropsis gaditana & 15.2 & 30.2 & - & - & - & 5.3 & - & 9.2 & - & 3.9 & 35.1 & \\
\hline Tetracystis intermedia & 21.3 & - & 5.9 & - & 22.4 & 10.6 & 21.6 & 7.6 & - & - & - & \\
\hline Scenedesmus obliquus & 21.78 & 5.95 & 3.96 & 0.68 & 0.45 & 17.93 & 21.74 & 3.76 & 0.21 & - & - & \multirow{2}{*}{$\begin{array}{l}\text { Gouveia and } \\
\text { oliveira, } 2008\end{array}$} \\
\hline Neochloris oleabundans & 19.35 & 1.85 & 1.74 & 0.96 & 0.98 & 20.29 & 12.99 & 17.43 & 2.1 & - & - & \\
\hline Botryococcus braunii & 21 & 2 & 6.5 & 15.2 & 2.9 & 3.2 & 13.6 & 33 & - & - & - & \multirow{2}{*}{$\begin{array}{l}\text { Schlagermann } \\
\text { et al., } 2012\end{array}$} \\
\hline Nannochloropsis salina & 37.5 & 23.3 & - & - & 0.9 & 11.9 & 1.5 & - & - & 3.3 & 15.3 & \\
\hline Nostoc commune & 43.5 & 11.3 & 0.4 & - & 1.5 & 6.9 & 19.3 & 16.3 & - & - & - & \multirow[t]{2}{*}{ Lang et al., 2011} \\
\hline Parietochloris incisa & 10 & 2 & 1 & 1 & 3 & 16 & 17 & 3 & - & 46 & 1 & \\
\hline Lauderia borealis & 12 & 21 & - & - & - & 3 & 1 & - & - & 1 & 3 & \multirow[t]{2}{*}{ Harwood, 2019} \\
\hline Phaeodactylum tricornutum & 19 & 25 & - & - & - & 8 & 6 & 1 & - & 1 & 18 & \\
\hline
\end{tabular}

Suchitra et al. (2019) [67] confirmed the presence of octadecadienoic acid, octadecenoic acid, and hexadecanoic acid methyl ester in Botryococcus sp. and Tetradesmus wisconsinensis, which are responsible for biodiesel production. The presence of phosphate usually hinders the transesterification process and leads to sulfur emissions from vehicles. So, due to the presence of high fatty acid content and lack of phosphorus and sulfur, TGAs are preferred over polar lipids for biofuel production (MacDougall et al., 2011) ${ }^{[43]}$. Algal species with rich TAG or oil content are referred to as oleaginous algae (Hu et al., 2008) ${ }^{[35]}$. The structure of the TAG molecule comprises a glycerol backbone and three fatty acids attached to it. Depending on the degree of unsaturation present in these attached fatty acid chains, they can be further classified as saturated fatty acid (SFA) and unsaturated fatty acid as Monounsaturated fatty acid (MUFA), and Polyunsaturated fatty acid (PUFA) (Sharma et al., 2018) ${ }^{[62]}$. TAG accumulation is linked with photosynthesis and increases with stress conditions like high salt concentration, heat stress, nutrient starvation, etc. Certain chemicals like Brefeldin A, lipase inhibitors, etc. can also be used to induce TAG accumulation. Specific acyltransferases are involved in the biosynthesis pathway of TAG. The acyl chains are 
sequentially added to the Glycerol-3- phosphate (Wase et al., 2018) ${ }^{[70]}$.

\section{Nile red staining}

Unlike traditional methods of analysis of lipids which are time-consuming, Nile red staining is relatively simple and easy to perform the technique. Staining with Nile red will not involve any extraction methods rather the whole algal cells are directly used for lipid analysis. Neutral lipids, due to its lower unsaturation have much importance in biofuel production. These are normally found as lipid droplets in the cytoplasm and are produced under unfavorable or stress conditions and at the end of the growth stage (Han et al., 2011) ${ }^{[31]}$. Nile red is a lipophilic dye with a heterocyclic structure. The fluorescence of the stain is highly dependent on the hydrophobicity of the environment (Malapascua et al., 2012) ${ }^{[44]}$. When Nile Red interacts with the lipid bodies in a hydrophobic environment, it emits intense fluorescence. But, the fluorescence is fully quenched in an aqueous environment (Halim and Webley, 2015) ${ }^{[30]}$. Due to its ease in use, it is used widely in the estimation of lipids in bacteria, yeasts, microalgae, etc. The earlier studies on the Nile Red staining failed and this may be due to the thick and rigid cell wall composition of the algae. This would have perhaps restricted the entry of the dye into the cells. To overcome such issues and to make use of Nile red as an ideal stain for lipid analysis, certain modifications are done to the process which showed the rise in the graph of the results in a positive way. This includes the use of dimethyl sulfoxide (DMSO) as a carrier that allows the entry of the stain at elevated temperatures (Chen et al., 2009) ${ }^{[12]}$.

The advantage of Nile Red over BODIPY 505/515 is that the latter has a strong background fluorescence which distorts the actual lipid fluorescence (Morschett et al., 2016) ${ }^{[49]}$. The guidelines for the standardization of Nile red staining for microalgae strains were formulated by Halim and Webley (2015) ${ }^{[30]}$. They further concluded that Nile red staining can be used as a quick diagnostic tool for screening hyper-lipid producing microalgae cells. Gerde et al. (2012) ${ }^{[24]}$ reported that Nile red staining can be utilized to quantify the cell disruption efficiency of heterotrophic microalgae via ultrasonication. They also found the Nile red fluorescence method as an instrumental for the rapid determination of the best extraction technique to maximize oil extraction. Suchitra et al. (2019) ${ }^{[67]}$ confirmed the presence of neutral lipid in microalgal cells via Nile red staining.

\section{Bodipy 505/515 staining}

BODIPY is a lipophilic fluorescent dye, which can be used as an alternative to Nile red dye. Algal cells stained with BODIPY shows stained green lipid bodies with red chloroplasts (Cooper et al., 2010) ${ }^{[16]}$. It belongs to a class of strong UV absorbing molecules with a sharp emission peak. Small modification to the structure of the dye results in different fluorescent and excitation properties (Rumin et al., 2015) ${ }^{[57]}$. The high lipid yielding cells can be identified and isolated microscopically via micromanipulator, flow cytometry, or fluorescence-activated cell sorter. The main advantage of BODIPY 505/515 is that it does not bind to cytoplasmic compartments other than lipid and chloroplast. Due to the high oil/water coefficient, it allows the stain to the lipid components of the live cells. The lipid probe is blue which can be distinguished from the green chloroplasts (Brennan et al., 2012) [10]. Encarnacao et al. (2018) [19] proposed a new fluorescent probe BODIPY BD-C12 to determine the lipid content in Nannochloropsis. It showed multicolor fluorescence and showed increased lipid content with nitrogen stress conditions. The advantages of this dye include high molar extinction coefficient, high fluorescent quantum yields, sharp emission bands, relative insensitivity to changes in $\mathrm{pH}$ and polarity, and good photochemical stability (Govender et al., 2012) ${ }^{[27]}$.

\section{Sudan black B staining}

Sudan Black B is a dark-colored non-fluorescent thermostable fat-soluble diazo dye that was first used for staining of neutral triglycerides and lipids by Lison (1934) ${ }^{[41]}$. Ru-rong et al. (2011) ${ }^{[58]}$ observed microalgal lipids by Sudan Black B staining and recorded maximum absorbance at a wavelength of $645 \mathrm{~nm}$. Kitcha and Cheirsilp (2011) ${ }^{[37]}$ Screened 23 lipid producing yeast strains by Sudan Black B test. The eight freshwater blooming green algae of keral were screened preliminarily for lipid richness by the Sudan Black B staining method (Santhosh et al., 2016) ${ }^{[59]}$.

\section{FTIR spectroscopy}

FT-IR (Fourier Transform Infrared Spectroscopy) can be used for lipid content determinations in algal as lipid, carbohydrate and protein have their absorbance at specific frequency regions in the mid-infrared zone (Lv et al., 2010) ${ }^{[42]}$. Dean et al. (2010) ${ }^{[17]}$ have demonstrated the use of Fourier transform infrared micro-spectroscopy for lipid and carbohydrate estimation from freshwater microalgae. It is a technique that provides information regarding changes taking place in-situ and in-vivo inside living cells. The strength and frequency of absorption are estimated with factors like the mass of atoms, bond type, symmetry, etc (Vidyadharani and Dhandapani, 2013) ${ }^{[68]}$. Ansari et al. (2019) ${ }^{[1]}$ performed FT-IR analysis of Scenedesmus obliquus which showed different absorption bands of various functional groups. The variations in the peak intensities correspond to changes in biochemical composition due to different nutrient conditions. It is reported that FT-IR is an efficient and rapid tool for monitoring algal lipid accumulation. Highly significant correlations were noticed between FT-IR and the Nile red based lipid measurement (Dean et al., 2010) ${ }^{[17]}$. Other than lipid estimation, FT-IR can also be used to analyze growth prediction, changes in elemental carbon allocation, and physiological responses to nutrient stress (Mayers and Shields, 2013) ${ }^{[46]}$. The advantages of this method over conventional chemical analyses include high reliability, sensitivity, and speed of measurement procedure (Wagner et al., 2010) ${ }^{[69]}$. Feng et al. (2013) [21] compared FT-IR and the Nile red with gravimetry for microalgal lipid determination. They further confirmed that Nile red is more appropriate for small samples when highfrequency screening is required.

\section{PAM fluorometry}

Pulse Amplitude Modulation (PAM) fluorescence gives information about the photosynthetic yield. The instrument (fluorometer) used is capable of measuring the intensity changes of fluorescence without disturbing the state of the sample (Schreiber et al., 2004) ${ }^{[61]}$. PAM can be used for qualitative estimation of the physiological characteristics of oxygenic photosynthesis e.g. linear and cyclic electron transfer (Schuurmans et al., 2015) ${ }^{[64]}$. It is not only a rapid and non-intrusive method but also can be used to determine properties like photoprotection and photoinhibition (Jebali et al., 2019) [36]. Ranglova et al. (2019) ${ }^{[55]}$ used the PAM fluorometry to analyze the rate of photosynthesis and its 
variables. They related it to the growth of the culture and used it for the estimation of suitable temperature for optimum growth of a particular strain.

The screening of microalgae bioprospecting has to be comprehensive in assessing the lipid producing potential as well as the kinetics of growth and tolerance. The success of downstream processing is dependent on reliable biochemical and physiological screening tools such as the Nile red staining, BODIPY lipid stain, FTIR spectroscopy, and PAM fluorometry.

\section{Sulfo-phospho-vanillin (SPV) method}

The colorimetric (SPV) method is known for its fast response and it is relatively easy in handling the samples. It was first introduced by Chabrol and Charonnat (1937) ${ }^{[11]}$. This method was widely used as standard protocol human cerebrospinal fluid estimation for the detection of total lipid content. Because of the reactivity of SPV with the human serum, it has a prominent role in the medical field. Mishra et al. (2014) ${ }^{[48]}$ used the SPV method for lipid estimation in microalgae like Chlorella sp., Nannochloropsis sp., etc. and was successfully employed as a direct quantitative measurement of algal lipids. It is a microplate assay where the reaction mixture is maintained in a 96-well plate throughout the assay. SPV when reacting with lipids, produces pink color, and the absorbance measured at $530 \mathrm{~nm}$ using spectrophotometric methods refer to the lipid concentration. The main reagents used include concentrated sulphuric acid, methanol, chloroform, ophosphoric acid. Phoshovanillin is prepared by mixing vanillin with phosphoric acid at standard proportions (Park et al., 2016) ${ }^{[51]}$.

Certain advantages are using this method which includes 1) absorbance reading is comparatively easy 2) less risk of handling the samples containing concentrated sulphuric acid and 3) color development and its intensity refer to the concentration of lipids present. So, this method can be used for the quantitative measurement of lipids (Cheng et al., 2010) ${ }^{[13]}$. SPV assay is sensitive to the degree of unsaturation and shows high intensities with high degrees of unsaturation present. One of the main disadvantages is that it may lead to false results if the unsaturation degree changes during the process or chemical treatment of the samples (Higgins et al., 2014) ${ }^{[33]}$.

\section{Mass spectrometry}

Mass spectrometry is a powerful analytical technique used to determine the molecular weight, chemical composition, the position of branching, and nature of substituents in the fatty acid structures of microalgal lipids. Many new strategies for Mass Spectrometry based analysis of lipids have been developed. Using the Matrix-Assisted Laser Desorption and Ionization Time-of-Flight (MALDI-TOF) Mass Spectrometry (MS) in combination with Thin-Layer Chromatography (TLC) technique, glycerol-trimethylhomoserine and phosphatidylethanolamine are exclusively detected in the green algae Chlamydomonas reinhardtii extracts, and phosphatidylcholine, a characteristic lipid of Cyclotella meneghiniana (Diatom) have been detected (Astrid et al., 2007) ${ }^{[4]}$. The Liquid Chromatography - Mass Spectrometry (LC-MS) is used to profile the total Glycolipids and Phospholipids of microalgal species of Chlamydomonas reinhardtii, Chlorella vulgaria, Nannochloropsis sp., Scenedesmus sp., and Schizochytrium limacinum (Linxing et al., 2015) ${ }^{[40]}$

\section{Raman spectroscopy}

Raman spectroscopy is a non-destructive method used to identify the components, determine the chemical composition and various properties of biomolecules in the individual algal cells. It is based on the principle of Raman scattering that takes place due to inelastic collision between photons and electrons. The difference in energy between incident photon and emitted photon generates Raman lines. Depending on the emitted frequency of the photons the lines generated are called Stokes lines, if their frequency of the emitted photon is less than the incident frequency of photons and anti stokes line if the frequency of emitted photons is greater than the incident frequency of photons. Depending on the number of scattered photons, the raman spectrum shows various peaks that change with changes in the characteristics of biomolecules in the sample. These characteristic peaks can be used to identify the structural components, or chemical composition of the sample (Niranjan and Vikas, 2012) ${ }^{[50]}$. Laser Tweezers Raman Spectroscopy (LTRS) is a combination of a near-IR optical trap and a Raman spectroscopy, used to obtain the Raman spectral library of lipid extract from microalgal cells (Huawen et al., 2011) ${ }^{[34]}$ (Figure 2).

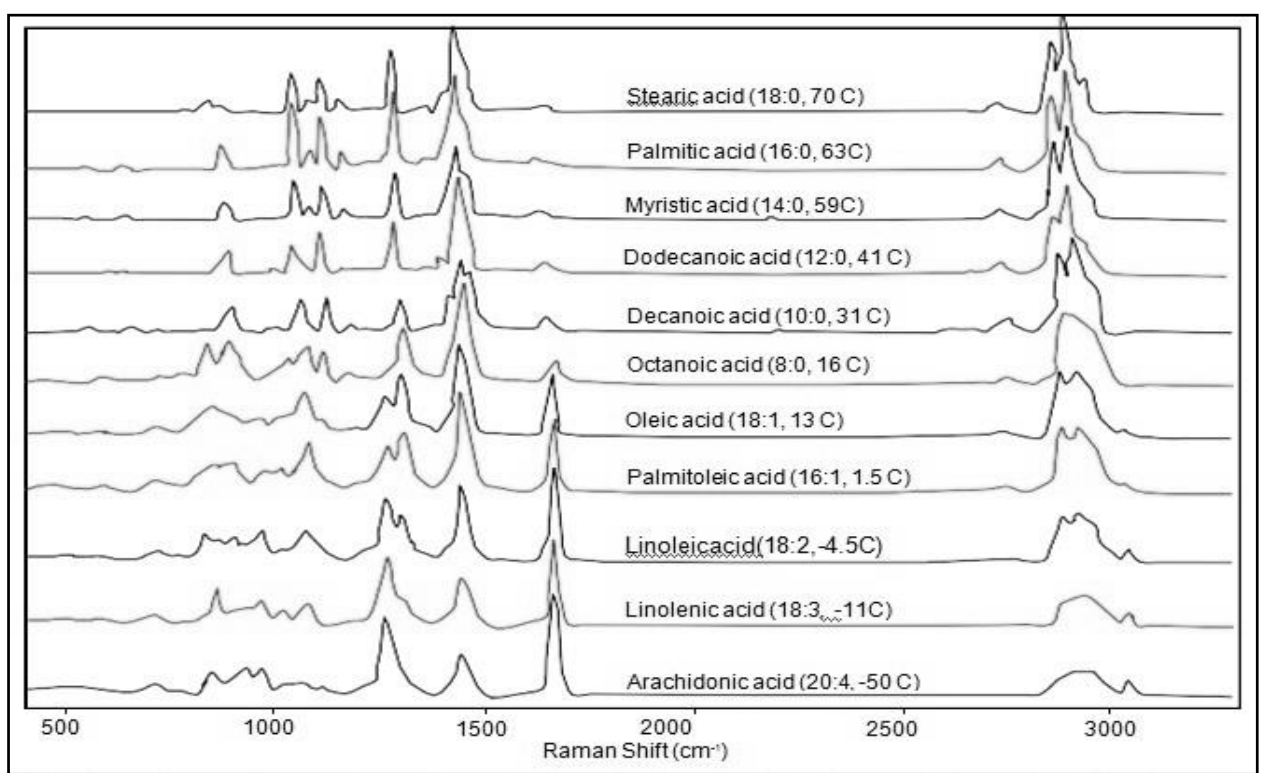

Fig 2: Raman spectral library of several single fatty acids typically found in algal lipid extracts $\sim 2454 \sim$ 
The Raman spectral peaks obtained from the lipid bodies of single microalgal cells determine the ratio of unsaturated-tosaturated carbon-carbon bonds in fatty acids (Table 2). Advances in Raman Spectroscopy techniques such as Surface Enhanced Raman Spectroscopy (SERS), Tip Enhanced Raman Spectroscopy (TERS), Coherent Anti-Stokes Raman
Spectroscopy (CARS) and Laser Tweezers Raman Spectroscopy (LTRS) enable us to identify the real-time changes in the microalgal cells and to detect the biomolecule changes in the algal cells in different environments (Niranjan and Vikas, 2012) ${ }^{[50]}$.

Table 2: Degree of lipid unsaturation in microalgae using Raman spectroscopy

\begin{tabular}{|c|c|c|c|c|}
\hline $\begin{array}{l}\text { S. } \\
\text { No }\end{array}$ & Microalgal Strains & $\begin{array}{c}\text { Raman Spectral } \\
\text { Peaks }\end{array}$ & Characteristics & References \\
\hline 1 & Botryococcus braunii & $\begin{array}{c}1650-1670 \mathrm{~cm}^{-1} \text { and } \\
2800-3000 \mathrm{~cm}^{-1} \text { peaks }\end{array}$ & $\begin{array}{c}\text { Double bond stretching peak in long chain unsaturated } \\
\text { hydrocarbons }\end{array}$ & Largeau et al., 1980 \\
\hline 2 & $\begin{array}{c}\text { Chlorella sorokiniana } \\
\text { Neochlorisoleo } \\
\text { abundans } \\
\end{array}$ & $\begin{array}{c}1650 \mathrm{~cm}^{-1} \text { peak } \\
2800-3000 \mathrm{~cm}^{-1} \text { peak }\end{array}$ & $\begin{array}{l}\mathrm{C}=\mathrm{C} \text { Stretching peak } \\
\mathrm{C}=\mathrm{C}-\mathrm{H} \text { vibration peak }\end{array}$ & Huang et al., 2010 \\
\hline 3 & $\begin{array}{l}\text { Botryococcus } \\
\text { sedeticus } \\
\text { Chlamydomonas sp. } \\
\text { Trachydiscus minutes }\end{array}$ & $\begin{array}{l}1656 \mathrm{~cm}^{-1} \text { peak } \\
1445 \mathrm{~cm}^{-1} \text { peak }\end{array}$ & $\begin{array}{l}\text { Cis } \mathrm{C}=\mathrm{C} \text { stretching mode proportional to no. of unsaturated } \\
\text { bonds. } \\
\mathrm{CH}_{2} \text { scissoring mode proportional to no. of saturated bonds. } \\
\text { Trachydiscus minutes have significantly higher content of } \\
\text { unsaturated fatty acids. }\end{array}$ & Samek et al., 2010 \\
\hline
\end{tabular}

\section{Near infrared reflectance spectroscopy}

Near Infrared Reflectance Spectroscopy (NIRS) is an analytical method in which the sample is irradiated with the near-infrared region of the electromagnetic spectrum (800$2500 \mathrm{~nm}$ ) and the reflected wavelength of light is recorded in the form of a spectrum. The spectrum contains information about the composition of the sample as different molecules absorb and reflect near-infrared light in a different wavelength. The NIRS technique is used to determine the TFA across three Chlorella species of Chlorella vulgaris, Chlorella protothecoides, and Chlorella zofingiensis (Bin et al., 2015) ${ }^{\text {[7]; }}$ using FAME as a proxy measurement the concentration of biomass and lipid was estimated in microalgal cultures of Kirchneriella sp. and Nannochloropsis sp. (Malcolm et al., 2014) ${ }^{[45]}$. The NIR combined with FTIR (Fourier Transform Infrared) is used for predicting the levels of spiked neutral and polar lipids in microalgae species of Nannochloropsis sp., Chlorococcum sp., Spirulina sp., and an unknown Diatom (Lieve and Edward, 2010) ${ }^{[39]}$. NIRS technique can bypass the involvement of cell disruption, oil extraction, and transesterification processes. Thus, it is a fast and non-destructive method that has great potential for screening purposes, in particular the high throughput screening of oleaginous microalgal fatty acids for biodiesel production (Bin et al., 2015) ${ }^{[7]}$.

\section{Hyper spectral imaging}

The traditional way of the gravimetric method to determine the lipid concentration of microalgae involves a set of chemical treatments which is a tedious and time-consuming process. Although the chemical analysis based on gravimetric method is accurate, it is difficult to apply in large scale industrial applications and the use of chemical treatment also increases the potential of environmental pollution. To address this problem many potential detection techniques have been proposed. Among them, hyperspectral imaging is an ecofriendly, nondestructive, fast, and real-time in situ method that is capable of visualizing the microalgal lipid concentration in live microalgal cultures. It helps in understanding the dynamic effect of nitrogen stress on the lipid content accumulation in microalgae Scenedesmus obliquus (Xiaoli et al., 2020) ${ }^{[71]}$. Hyperspectral imaging is an extension of near-infrared spectroscopy, obtained by recording the reflections of hundreds of different bands of the electromagnetic spectrum from the biological samples (Akin and Kemal, 2020) [5]. The hyperspectral imaging of microalgae revealed a continuous process of lipid accumulation from live algal cells under different conditions, which to the best of our knowledge has not been investigated in the literature. The hyperspectral image method provides an intuitive visual way to display the lipid accumulation of algae, which has enormous potential in both microalgae-based industrial and biofuel research (Xiaoli et al., 2020) ${ }^{[71]}$.

\section{NMR spectroscopy}

High resolution nuclear magnetic resonance spectroscopic technique offers many advantages over existing analytical methods. Sarpal et al. (2015) ${ }^{[60]}$ have developed the NMR technique for characterization and determination of lipid content and fatty acid profile of microalgal cultures. NMR method for neutral lipid estimation is a rapid and economical means for lipid estimation of algal cultures. It is a nondestructive method of lipid estimation. This method can be used for both qualitative and quantitative analysis of lipids. The basic principle of this technique is related to the magnetic properties of the atomic nuclei. The nucleus of every atom is electrically charged and each nucleus of the elemental isotopes has its characteristic spin. For a particular nucleus, two spin states exist when an external magnetic field is applied. The difference in the energy between these spin states differs with the magnetic field applied and the nucleus which is being studied. When a sample is subjected to irradiation with radiofrequency energy exactly to the spin state separation of the particular nuclei, it leads to the excitation of the set of nuclei from its lower energy state to its higher energy state (Xu et al., 2015) ${ }^{[72]}$.

Time Domain (TD)-NMR is the cheaper and the simplified version of the traditional NMR technique. The frequency range of 2 to $25 \mathrm{MHz}$ is commonly used to operate it (Falch et al., 2006) ${ }^{[20]}$. It mainly focuses on the relaxation times of the hydrogen nuclei in different phases of the samples. Gao et al. (2008) ${ }^{[23]}$ applied the Spin-echo NMR pulse sequence for separating lipid hydrogen nuclei signals from others. Recently, benchtop NMR spectroscopy devices have emerged to improve accessibility and cost. Using this, lipid estimation can be done without disturbing the biological processes of the algal cells (Bouillauda et al., 2019) ${ }^{[8]}$. Algal lipid estimation via NMR provides additional information with high accuracy and precision (Landkhorst and Chang, 2018) ${ }^{[38]}$. 


\section{Gravimetric method}

It is one of the oldest methods of lipid estimation. The procedure involves the extraction of lipids from the microalgal cells followed by quantification. The two-step extraction process involves methanol, chloroform, and water for phase separation and quantification. The health and safety issues, as well as environmental concerns due to the use of hazardous chemicals like methanol and chloroform, are considered as serious problem (Elsey et al., 2007; Breil et al., 2017) ${ }^{[18 ; 9]}$. This method stands as a reference for newly emerging methods (Chen and $\mathrm{Wu}, 2011)^{[14]}$. Many new techniques and instruments have emerged due to certain disadvantages of this method like time-consuming, laborintensive, requires a large number of samples and procedure involves certain hazardous chemicals. So, it cannot be used for large-scale purposes (Gong and Jiang, 2011) ${ }^{[26]}$.

\section{Chromatographic techniques}

Chromatography is a technique used in the separation of a mixture of chemical substances into its components. Among many types of chromatographic techniques High Performance Liquid Chromatography, Gas Chromatography Mass Spectrometry and Thin Layer Chromatography are widely used in lipid estimations. These techniques are usually coupled with other techniques for accuracy which include spectroscopy. The separation principle lies in the differing affinities of each component of the mixture loaded for the matrix.

TLC: The absorbent material used is silica which has high quality in bonding. Quantitative estimation can be done by direct recovery from the loaded plate or after recovering the individual components from the plate (Patel et al., 2019) ${ }^{[52]}$. On the chromoplate, silica gel is most commonly used as the stationary phase (solid) and the loading component (sample) acts as the mobile phase (liquid). Several modifications like using Magnesium silica, Boric acid, Silver nitrate, etc. as stationary phases have been done to improve the resolution (Peterson and Cimmings, 2006) ${ }^{[53]}$.

HPLC: It is the most widely used technique among other chromatographic methods. Advantages include high specificity, sensitivity, good resolution, and speed. This method decreases the sample exposure to atmospheric oxygen, which remains as an advantage over TLC (Peterson and Cimmings, 2006) ${ }^{[53]}$. The additional advantage is that it is a non-destructive method and samples can be collected later (Gomes et al., 2018) ${ }^{[25] .}$

GC: Lipid profiling using GC is usually coupled with Mass Spectroscopy (MS). The samples should be pre-treated to increase its polarity volatility before injection. To avoid contamination, splitless injections are used (Fusuhashi and Weckwerth, 2013) ${ }^{[22]}$. This method is used to differentiate the volatile compounds with semi-volatile compounds. GC coupled with MS (GC-MS) has a high spectral resolution (Gomes et al., 2018) ${ }^{[25]}$.

\section{Conclusions}

There are many methods for lipid estimation from algae and each method has its advantages and disadvantages as mentioned in Table 3. If rapid screening of algal lipid is required, Nile red spectrofluorometric method can be used. The quantification of algal lipid depends mainly on the method used viz., conventional and non-conventional method. The non-conventional methods like NMR, spectroscopy, etc are more accurate and less time consuming compared to conventional methods.

Table 3: Advantages and Disadvantages of various methods of lipid estimation

\begin{tabular}{|c|c|c|c|}
\hline S. No & Methods & Advantages & Disadvantages \\
\hline 1 & Nile Red staining & $\begin{array}{ll}\text { - } & \text { Fast screening of potential oleaginous microalgae } \\
\text { - } & \text { Stains intracellular neutral lipids (TAG) }\end{array}$ & $\begin{array}{ll}\text { - } & \text { Limited photostability } \\
\text { - } & \text { Interference with chlorophyll } \\
\text { - } & \text { Difficulty of permeation for some species }\end{array}$ \\
\hline 2 & $\begin{array}{l}\text { BODIPY 505/515 } \\
\text { Staining }\end{array}$ & $\begin{array}{l}\text { Crosses cell membrane easily. } \\
\text { Do not bind to cytoplasmic compartments other than lipid } \\
\text { bodies (green fluorescence) and chloroplast (red } \\
\text { fluorescence) } \\
\text { Insensitive to pH and polarity of the environment }\end{array}$ & $\begin{array}{l}\text { - Background fluorescence of the dye in the } \\
\text { medium } \\
\text { Failure to quantify neutral lipids between } \\
\text { rich and low oil strains }\end{array}$ \\
\hline 3 & Sudan black B staining & - Stains neutral lipids and phospholipids & $\begin{array}{l}\text { - The thickness of the section may affect the } \\
\text { intensity of the staining }\end{array}$ \\
\hline 4 & $\begin{array}{c}\text { Sulpho-Phospho- } \\
\text { Vanillin (SPV) method }\end{array}$ & Requires only a small amount of target sar & - Time intensive and costly \\
\hline 5 & MALDI TOF MS & $\begin{array}{l}\text { - Simple, fast and sensitive technique. } \\
\text { Sample impurities, such as salts and detergents are } \\
\text { tolerated to high extent. }\end{array}$ & $\begin{array}{l}\text { Individual Phospholipid classes } \\
\text { (Phosphatidylcholine [PC], Sphingomyelin } \\
\text { [SM], Lysophosphatidylcholine [LPC]) are } \\
\text { detected with different sensitivities. } \\
\text { Signal suppression of lipids with lower ion } \\
\text { yield }\end{array}$ \\
\hline 6 & Raman Spectroscopy & 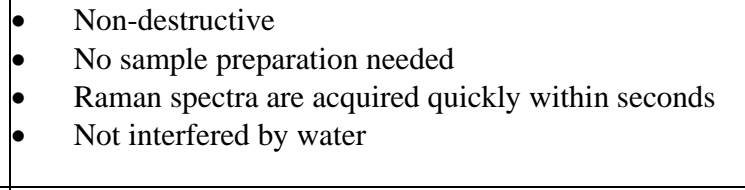 & $\begin{array}{l}\text { Do not detect lipid composition in large algal } \\
\text { cultures (only detects in single cells) } \\
\text { sample heating through the intense laser } \\
\text { radiation can destroy the sample } \\
\text { - Fatty acid profiling cannot be done }\end{array}$ \\
\hline 7 & $\begin{array}{l}\text { Near Infrared } \\
\text { Reflectance } \\
\text { Spectroscopy (NIRS) }\end{array}$ & 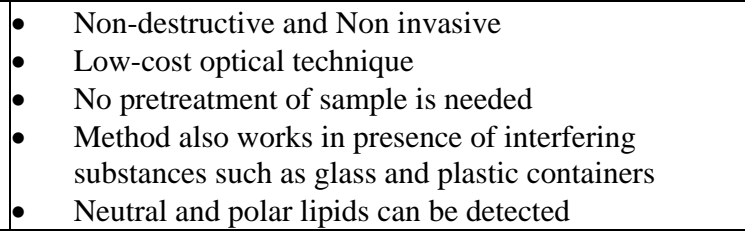 & $\begin{array}{l}\text { - } \quad \text { Fatty acid profiling cannot be done } \\
\text { - } \\
\text { - } \\
\text { Lack in structural interpretative value } \\
\text { (difficult to identify unknowns) }\end{array}$ \\
\hline 8 & $\begin{array}{l}\text { Nuclear Magnetic } \\
\text { Resonance (NMR) }\end{array}$ & $\begin{array}{ll}\text { - } & \text { Non-destructive } \\
\text { - } & \text { Direct,quantitative analysis of virtually all }\end{array}$ & $\begin{array}{ll}\text { - } & \text { Expensive equipment. } \\
\text { - } & \text { Relatively low sensitivity. }\end{array}$ \\
\hline
\end{tabular}




\begin{tabular}{|c|c|c|c|}
\hline & spectroscopy & $\begin{array}{l}\text { Phospholipids } \\
\text { - Continuous lipid analysis from live algal cells under } \\
\text { different conditions } \\
\text { - Neutral and polar lipids can be detected }\end{array}$ & $\begin{array}{l}\text { - High concentrations of detergent needed } \\
\text { Crowded spectra in the case of lipid } \\
\text { mixtures. }\end{array}$ \\
\hline 9 & $\begin{array}{c}\text { Thin Layer } \\
\text { Chromatography (TLC) }\end{array}$ & $\begin{array}{l}\text { - } \quad \text { Simple, fast and inexpensive } \\
\text { - } \quad \text { Non volatile compounds can be seperated }\end{array}$ & $\begin{array}{ll}\text { - } & \text { Low resolution } \\
\text { Very difficult to differentiate individual fatty } \\
\text { acids }\end{array}$ \\
\hline 10 & $\begin{array}{c}\text { High Performance } \\
\text { Liquid Chromatography } \\
\text { (HPLC) }\end{array}$ & $\begin{array}{ll}\text { - } & \text { Individual lipid classes can be differentiated } \\
\text { - } & \text { Fatty acid profiling can be done } \\
\text { - } & \text { Higher resolution and speed of analysis }\end{array}$ & $\begin{array}{ll}\text { - } & \text { More expensive } \\
\text { - } & \text { Lack of universal detector } \\
& \text { Less separation efficiency than GC }\end{array}$ \\
\hline 11 & $\begin{array}{c}\text { Gas Chromatography } \\
\text { (GC) }\end{array}$ & 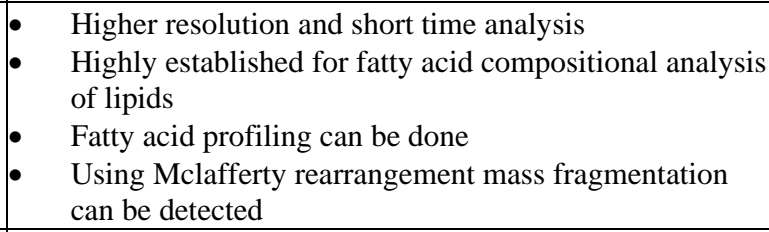 & $\begin{array}{l}\text { Purification and processing of samples are } \\
\text { required } \\
\text { Only volatile and thermally stable } \\
\text { compounds can be separated. }\end{array}$ \\
\hline 12 & $\begin{array}{c}\text { Hyper spectral imaging } \\
\text { technique }\end{array}$ & $\begin{array}{l}\text { Creates images using hundreds and thousands of } \\
\text { narrow band } \\
\text { Higher level of spectral detail in hyperspectral images } \\
\text { gives better capability to see the unseen }\end{array}$ & $\begin{array}{ll}\text { - } & \text { Cost and complexity } \\
\text { - } & \text { Large data storage capacities are needed }\end{array}$ \\
\hline
\end{tabular}

Acknowledgements This work is financially supported by the SERB DST project (EEQ/2018/001463)

\section{Compliance with ethical standards}

Conflict of interest Author (s) declares that they do not have any conflict of interest.

\section{ORCID}

Suchitra Rakesh https://orcid.org/0000-0002-4357-4042

\section{References}

1. Ansari FA, Ravindran B, Gupta SK, Nasrd M, Rawata I, Bux F. Techno-economic estimation of wastewater phycoremediation and environmental benefits using Scenedesmus obliquus microalgae. J Environ. Manage. 2019; 240:293-302.

2. Alam F, Datea A, Rasjidina R, Mobinb S, Abdul Baquic HM. Biofuel from algae- Is it a viable alternative? Procedia. Eng. 2012; 49:221-227.

3. Aratboni HA, Rafiei N, Granados RG, Alemzadeh A, Morones-Ramirez JR. Biomass and lipid induction strategies in microalgae for biofuel production and other applications. Microb. Cell. Fact. 2019; 18:178.

4. Astrid V, Christian W, Reimund G, Rosmarie S, Jurgen $\mathrm{S}$. The lipid composition of the unicellular green alga Chlamydomonas reinhardtii and the diatom Cyclotella meneghiniana investigated by MALDI-TOF MS and TLC. Chem. Physic. Lipid. 2007; 150:143-155.

5. Akin O, Kemal P. Deep Learning Applications for Hyperspectral Imaging: A Systematic Review. J Instit. Electron. Comput. 2020; 2:39-56.

6. Beisson YL, Harwood JL. The lipid biochemistry of eukaryotic algae. Prog. Lip. Res. 2019; 74:31-68.

7. Bin L, Jin L, Tianpeng C, Bo Y, Yue J, Dong W et al. Rapid Characterization of Fatty Acids in Oleaginous Microalgae by Near-Infrared Spectroscopy. Internat. J Mole. Sci. 2015; 16:7045-7056.

8. Bouillauda D, Herediab V, Cordiera TC, Drouinb D, Charriera B, Goncalvesb O et al. Benchtop flow NMR spectroscopy as an online device for the in vivo monitoring of lipid accumulation in microalgae. Algal Res. 2019; 43:101624.

9. Breil C, Vian MA, Zemb T, Kunz W, Chemat F. Bligh and Dyer and Folch Methods for Solid-Liquid-Liquid
Extraction of Lipids from Microorganisms. Comprehension of Solvation Mechanisms and towards Substitution with Alternative Solvents. Int. J Mol. Sci. 2017; 18:708.

10. Brennan L, Fernández AB, Mostaert AS, Owende P. Enhancement of BODIPY505/515 lipid fluorescence method for applications in biofuel-directed microalgae production. J Microbiol. Method. 2012; 90:137-143.

11. Chabrol EC, Charonnat R. Une nouvelle reaction pour l'e'tudes des lipides: l'oleidemie. La Presse Medical. 1937; 45:1713-1714.

12. Chen W, Zhang C, Song L, Sommerfeld M, Hu Q. A high throughput Nile red method for quantitative measurement of neutral lipids in microalgae. J Microbiol. Method. 2009; 77:41-47.

13. Cheng YS, Zheng Y, VanderGheynst JS. Rapid Quantitative Analysis of Lipids Using a Colorimetric Method in a Microplate Format. Lipid. 2010; 46:95-103.

14. Chen $\mathrm{Y}, \mathrm{Wu} \mathrm{Q}$. Production of Biodiesel from Algal Biomass: Current Perspectives and Future. Biofuels Alt. Feedstoc. Convers. Proc. 2011, 399-413.

15. Chen Z, Wang L, Qiu S, Ge S. Determination of Microalgal Lipid Content and Fatty Acid for Biofuel Production. Biomed. Res. Int. 2018, 1503126.

16. Cooper MS, Hardin WR, Petersen TW, Cattolica RA. Visualizing "green oil" in live algal cells. J. Biosci. Bioeng. 2010; 109:198-201.

17. Dean AP, Sigee DC, Estrada B, Pittman JK. Using FTIR spectroscopy for rapid determination of lipid accumulation in response to nitrogen limitation in freshwater microalgae. Bioresour. Technol. 2010; 101:4499-4507.

18. Elsey D, Jameson D, Raleigh B, Cooney MJ. Fluorescent measurement of microalgal neutral lipids. J Microbiol. Method. 2007; 68:639-642.

19. Encarnacao T, Arranja CT, Cova TG, Pais AC, Campos MG, Sobral AN et al. Monitoring oil production for biobased feedstock in the microalga Nannochloropsis sp.: a novel method combining the BODIPY BD-C12 fluorescent probe and simple image processing. J. Appl. Phycol. 2018; 30:2273-2285.

20. Falch E, Storseth TR, Aursand M. Multi-component analysis of marine lipids in fish gonads with emphasis on 
phospholipids using high resolution NMR spectroscopy. Chem. Phys. Lipid. 2006; 144:4-16.

21. Feng GD, Zhang F, Cheng LH, Xu XH, Zhang L, Chen HL. Evaluation of FT-IR and Nile Red methods for microalgal lipid characterization and biomass composition determination. Bioresour. Technol. 2013; 128:107-112.

22. Furuhashi T, Weckwerth W. Introduction to Lipid (FAME) Analysis in Algae Using Gas ChromatographyMass Spectrometry, The Handbook of Plant Metabolomics, First Edition. Edited by Wolfram Weckwerth and Günter Kahl \# 2013 Wiley-VCH Verlag GmbH \& Co. KGaA. Published by Wiley-VCH Verlag $\mathrm{GmbH} \& \mathrm{Co} . \mathrm{KGaA}$.

23. Gao C, Xiong W, Zhang Y, Yuan W, Wu Q. Rapid quantification of lipid in microalgae by time-domain nuclear magnetic resonance. J Microbiol. Method. 2008; 75:437-440.

24. Gerde JA, Lomboy MM, Yao L, Grewell D, Wang T. Evaluation of microalgae cell disruption by ultrasonic treatment. Bioresour. Technol. 2012; 125:175-181.

25. Gomes J, Batra J, Chopda VR, Kathiresan P, Rathore AS. Monitoring and Control of Bioethanol Production from Lignocellulosic Biomass. Waste Bioref Potential Perspec. 2018, 27-749.

26. Gong Y, Jiang M. Biodiesel production with microalgae as feedstock: from strains to biodiesel. Biotechnol. Lett. 2011; 33:1269-1284.

27. Govender T, Ramanna L, Rawat L, Bux F. BODIPY staining, an alternative to the Nile Red fluorescence method for the evaluation of intracellular lipids in microalgae. Bioresour. Technol. 2012; 114:507-511.

28. Guo M, Song W, Buhain J. Bioenergy and biofuels: History, status, and perspective. Renew. Sust. Energ. Rev. 2015; 42:712-725.

29. Gupta V, Ratha SK, Sood A, Chaudhary V, Prasanna R. New insights into the biodiversity and applications of cyanobacteria (blue-green algae)-Prospects and challenges. Algal Res. 2013; 2:79-97.

30. Halim R, Webley PA. Nile Red Staining for Oil Determination in Microalgal Cells: A New Insight through Statistical Modelling. Int. J Chem. Eng. 2015: Article ID 695061.

31. Han Y, Wen Q, Chen Z, Li P. Review of Methods Used for Microalgal Lipid-Content Analysis. Energ. Procedia. 2011; 12:944-950.

32. Held P, Raymond K. Applications Department, BioTek Instruments, Inc., Winooski, VT. Determination of Algal Cell Lipids Using Nile Red Using Microplates to Monitor Neutral Lipids in Chlorella Vulgaris. Biofuel Res, 2011.

33. Higgins BT, Dunwoody AT, Labavitch JM, Vander Gheynst JS. Microplate assay for quantitation of neutral lipids in extracts from microalgae. Anal. Biochem. 2014; 465:81-89.

34. Huawen W, Joanne VV, Ann EO, Atul NP, Blake AS, Seema S. In-vivo lipidomics using single-cell Raman spectroscopy. PNAS 2011; 108(9):3809-3814.

35. Hu Q, Sommerfeld M, Jarvis E, Ghirardi M, Posewitz M, Seibert M, Darzins A. Microalgal triacylglycerols as feedstocks for biofuel production: perspectives and advances. Plant J. 2008; 54:621-639.

36. Jebali A, Acien FG, Ruiz NJ, Gomez C, Fernandez-Sevilla JM, Mhiri N et al. Evaluation of native microalgae from Tunisia using the pulse-amplitude-modulation measurement of chlorophyll fluorescence and a performance study in semi-continuous mode for biofuel production. Biotechnol. Biofuel. 2019; 12:119.

37. Kitcha S, Cheirsilp B. Screening of oleaginous yeasts and optimization for lipid production using crude glycerol as a carbon source. Energ. Procedia. 2011, 274-282.

38. Lankhorst PP, Chang A. The Application of NMR in Compositional and Quantitative Analysis of Oils and Lipids. Mod. Magn. Reson. 2018, 1743-1764.

39. Lieve MLL, Edward JW. Feasibility of Spectroscopic Characterization of Algal Lipids: Chemometric Correlation of NIR and FTIR Spectra with Exogenous Lipids in Algal Biomass. Bioenerg. Res. 2010; 4:22-35.

40. Linxing Y, Jose AG, Show LL, Tong W, Abdel KH. Microalgae Lipid Characterization. J Agri. Food Chem. 2015; 63(6):1773-1787.

41. Lison L. Sur de nouveaux color ants histologique specifiques des lipides. Compt. Rend. Soc. Biol. 1934; 115:202-205.

42. Lv JM, Cheng LH, Xu XH, Zhang L, Chen HL. Enhanced lipid production of Chlorella vulgaris by adjustment of cultivation conditions. Bioresour. Technol. 2010; 101:6797-6804.

43. MacDougall KM, McNichol J, McGinn PJ, O’Leary SJB, Melanson JE. Triacylglycerol profiling of microalgae strains for biofuel feedstock by liquid chromatographyhigh resolution mass spectrometry. Anal. Bioanal. Chem. 2011; 401:2609-2616.

44. Malapascua JR, Chou HN, Lu WJ, Lan JC. Development of an indirect method of microalgal lipid quantification using a lysochrome dye, Nile red. Afr. J Biotechnol. 2012; 11(70):13518-13527.

45. Malcolm RB, Dion MFF, Graeme AD, Susan IB. Assessing near-infrared reflectance spectroscopy for the rapid detection of lipid and biomass in microalgae cultures. J Appl. Phycol. 2014; 26:191-198.

46. Mayers JJ, Shields RJ. Rapid determination of bulk microalgal biochemical composition by FourierTransform Infrared spectroscopy. Bioresour. Technol. 2013; 148:215-220.

47. Menard SA, Amirsadeghi M, French WT, Boopathy R. A review on microbial lipids as a potential biofuel. Bioresour. Technol. 2018; 259:451-460.

48. Mishra SK, Suh WI, Farooq W, Moon M, Anupama S, Park MS et al. Rapid quantification of microalgal lipids in aqueous medium by a simple colorimetric method. Bioresour. Technol. 2014; 155:330-333.

49. Morschett H, Wiechert W, Oldiges M. Automation of a Nile red staining assay enables high throughput quantification of microalgal lipid production. Microb. Cell Fact. 2016; 15:34.

50. Niranjan P, Vikas T. Raman Spectroscopy of Algae: A Review. J. Nanomedic. Nanotechnol. 2012; 3:131.

51. Park J, Jeong HJ, Yoon EY, Moon SJ. Easy and rapid quantification of lipid contents of marine dinoflagellate using the sulpho-phospho-vanillin method. Algae. 2016; 31(4):391-401.

52. Patel A, Antonopoulou L, Enman J, Rova U, Christakopoulos P, Matsakas L. Lipids detection and quantification oleaginous microorganisms: an overview of the current state of the art. BMC Chem. Eng. 2019; $1: 13$.

53. Peterson BL, Cummings BS. A review of chromatographic methods for the assessment of 
phospholipids in biological samples. Biomed. Chromatogr. 2006; 20:227-243.

54. Parveen K, Sharma PK, Sharma PK, Sharma D. Microalgal Lipids: A Potential Source of Biodiesel. J Innov. Pharm. Biol. Sci. 2015; 2(2):135-143.

55. Ranglova K, Lakatos GE, Camara Manoel JA, Grivalský T, Masojídek J. Rapid screening test to estimate temperature optima for microalgae growth using photosynthesis activity measurements. Folia. Microbiol. 2019; 64:615-625.

56. Rajkumar R, Yaakob Z, Takriff MS. Potential of the Micro and Macro Algae for Biofuel Production: A Brief Review. Bio. Resour. 2014; 9(1):1606-1633.

57. Rumin J, Bonnefond H, Jean BS, Rouxel C, Sciandra A, Bernard $\mathrm{O}$ et al. The use of fluorescent Nile red and BODIPY for lipid measurement in microalgae. Biotechnol. Biofuel. 2015; 8:42.

58. Ru-rong L, Bing-Peng X, Wen-xuan C. Rapid detection of microalgal lipid content through Sudan black B staining. J. Appl. Oceanogr. 2011; 2:023.

59. Santhosh K, Prasanthkumar S, Ray JG. Experimental assessment of productivity, oil-yield and oil-profile of eight different common freshwater-blooming green algae of Kerala. Biocatal. Agric. Biotechnol. 2016; 8:270-277.

60. Sarpal AS, Teixeira CL, Silva PM, Lima GM, Silva SR, Monteiro TV et al. Determination of lipid content of oleaginous microalgal biomass by NMR spectroscopic and GC-MS techniques. Anal. Bioanal. Chem. 2015; 407:3799-3816.

61. Schreiber U, Botanik L, Sachs JV. Pulse-AmplitudeModulation (PAM) Fluorometry and Saturation Pulse Method: An Overview. Chloro. a Fluores. 2004, 279-319.

62. Sharma PK, Saharia M, Srivastava R, Kumar S, Sahoo L. Tailoring microalgae for efficient biofuel production. Front. Mar. Sci. 2018; 5:382.

63. Singh NK, Dhar DW. Microalgae as second generation biofuel. A review. Agro. Sust. Developm. 2011; 31:605629.

64. Schuurmans RM, Alphen PV, Schuurmans JM, Matthijs HCP, Hellingwerf KJ. Comparison of the Photosynthetic Yield of Cyanobacteria and Green Algae: Different Methods Give Different Answers. PLoS ONE. 2015; 10(9):e0139061.

65. Suchitra R, Saxena S, Dhar DW, Prasanna R, Saxena AK. Comparative evaluation of inorganic and organic amendments for their flocculation efficiency of selected microalgae. J Appl. Phycol. 2014; 26:399-406.

66. Suchitra R, Dhar DW, Prasanna R, Saxena AK, Saha S, Shukla $\mathrm{M}$ et al. Cell disruption methods for improving lipid extraction efficiency in unicellular microalgae. Eng. Life Sci. 2015; 15:443-447.

67. Suchitra R, Karthikeyan S, Dhar DW. Bioprospecting of indigenously isolated microalgae for biodiesel production. Agric. Res. J. 2019; 56(3):541-546.

68. Vidyadharani G, Dhandapani R. Fourier transform infrared (FTIR) spectroscopy for the analysis of lipid from Chlorella vulgaris. Elixir. Appl. Biol. 2013; 61:16753-16756.

69. Wagner H, Liu Z, Langner U, Stehfest K, Wilhelm C. The use of FTIR spectroscopy to assess quantitative changes in the biochemical composition of microalgae. J. Biophot. 2010, 1-10.

70. Wase N, Black P, Russo CD. Innovations in improving lipid production: Algal chemical genetics. Prog. Lipid Res. 2018; 71:101-123.
71. Xiaoli L, Kai C, Yong H. In-situ and non-destructive detection of the lipid concentration of Scenedesmus obliquus using hyperspectral imaging technique. Alga. Res. 2020; 45:101680.

72. $\mathrm{Xu} \mathrm{J,} \mathrm{Riccioli} \mathrm{C,} \mathrm{Sun} \mathrm{D.} \mathrm{An} \mathrm{Overview} \mathrm{on} \mathrm{Non-}$ destructive Spectroscopic Techniques for Lipid and Lipid Oxidation Analysis in Fish and Fish Products. Comp. Review. in Food Sci. Food Safety. 2015; 14(4):466-477.

73. Yan Y, Li X, Wang G, Gui X, Li G, Su F, Wang X, Liu T. Biotechnological preparation of biodiesel and its highvalued derivatives: A review. Appl. Energ. 2014; 113:1614-1631. 